\title{
Memoria, Procesos Identitarios y Pedagogías: El Caso Chileno
}

\section{Memory, Identity Processes and Pedagogies: The Chilean Case}

\author{
Graciela Rubio ${ }^{1 *}$ \\ Jorge Osorio ${ }^{2}$
}

${ }^{1}$ Universidad de Valparaíso. ${ }^{2}$ Universidad de Valparaíso

\begin{abstract}
El campo de los estudios de la memoria sobre la violación de los derechos humanos en América Latina está generando aperturas disciplinares críticas en la historia, las ciencias sociales y la educación. En particular, en este artículo se analiza la "pedagogía de la memoria" que se desarrolla desde las organizaciones de víctimas de la violencia política. Su característica principal es que está basada en una problematización del pasado reciente (dictaduras y transiciones a la democracia) en el marco de los procesos existenciales y políticos de las organizaciones que agrupan a las víctimas, a sus familiares e intelectuales de apoyo.
\end{abstract}

Descriptores: Historia contemporánea, Derechos humanos, Memoria colectiva, Identidad, Educación ciudadana.

The field of memory studies on human rights violations in Latin America is promoting new critical disciplinary areas in history, social sciences, and education. This article particularly analyzes "pedagogy of memory", which is developed from organizations in support of victims of political violence. The main characteristic of these organizations is that they are based on a problematization of the recent past (dictatorships and transitions to democracy) in a framework that considers the organizations' existential and political processes of the victims, their relatives and intellectual support

Keywords: Contemporary history, Human rights, Collective memory, Identity, Citizen education. 


\section{Introducción}

El presente artículo forma parte de un programa de investigación de los autores que se viene desarrollando desde inicios del actual siglo destinado a relevar los procesos de constitución de organizaciones y movimientos de recuperación de la memoria histórica relacionadas con las violaciones y represión sufrida por militantes políticos, defensoresas de los derechos humanos, organizaciones ciudadanas y religiosas, agrupaciones de familiares de las víctimas de las políticas represivas y de exterminio de las dictaduras militares, en particular de la dictadura militar chilena y las asociaciones artísticas, culturales y educacionales que configuran el campo de los trabajos de la memoria (Jelin, 2002; Osorio y Rubio, 2006; Rubio, 2013). Desde 1990 se han desarrollado en Chile políticas de la memoria que han pretendido integrar a la institucionalidad democrática legislaciones, actos reparatorios e iniciativas educacionales que, junto con el trabajo del sistema judicial, permitan avanzar en justicia, verdad y reparación con las víctimas de las violaciones de los derechos humanos desde el golpe militar de septiembre de 1973. Estas políticas de la memoria han sido el resultado de disputados procesos de negociación entre las fuerzas políticas que han dado sustento al modelo de gobernabilidad post 1990, así como de particulares políticas de contención de las instituciones militares. Sin embargo, tales políticas no se han manifestado solamente en el ámbito de lo gubernamental y de lo jurídico sino también en la configuración de un movimiento social que ha definido su identidad y razón de ser en la generación de condiciones ciudadanas y culturales para que tales políticas de la memoria radicalicen éticamente la responsabilidad del Estado en relación al reconocimiento de las víctimas, sus familiares y sus organizaciones de pertenencia haciendo del atributo memorial de la democracia un contenido central de la recuperación institucional en la llamada transición democrática.

En este artículo nuestro propósito es analizar los procesos de construcción del atributo memorial de la ciudadanía democrática desde las acciones y contenidos éticos, políticos y pedagógicos elaborados las organizaciones de las víctimas, y sus familiares y de las entidades que se han involucrado en recuperar, preservar y transmitir intergeneracionalmente las memorias de la represión y de las violaciones de los derechos humanos, a través de diversos dispositivos políticos, culturales, pedagógicos, artísticos, literarios, documentales y museológicos.

La constitución de este movimiento memorial, sus definiciones identitarias y los rangos de su producción histórica han convergido, no sin controversias, con los estudios de la pasado reciente, con sus sujetos académicos y con los argumentos disciplinarios de la historia , haciendo del campo de los estudios de la memoria un ámbito de disputa y politización de la actividad historiográfica, así de convergencia de diversas modalidades de referirse al pasado reciente, desde el testimonio y la memoria de las víctimas y de las producciones híbridas acerca del sentido del recuerdo de las violaciones de los derechos humanos, tales como las performances en espacios públicos, las obras dramáticas, la creación literaria-memorial, la educación escolar y popular, la resignificación- reapropiación de sitios memoriales o sitios de conciencia vinculados a antiguos centros de detención o lugares en los cuales se cometieron asesinatos políticos. La práctica de la recuperación de la memoria histórica de la represión en cuanto experiencia va más allá del testimonio de las víctimas y se constituye en una fuente de ampliación del repertorio de la ciudadanía democrática en cuanto manifestaciones de vigilancia e imputación ética de las instituciones y del poder político (Rosanvallon, 2007; Balibar,2013) En este 
artículo vamos a referirnos especialmente a la dimensión pedagógica de los movimientos memoriales tanto a sus propuestas como a los desafíos que provoca a los sistemas públicos de educación y a la construcción de renovadas culturas políticas en el país.

\section{La cuestión del pasado reciente y los procesos de construcción memorial}

\subsection{Pasado reciente en Chile: Políticas identitarias y movimientos memoriales. Relevancia y complejidad}

Las prácticas de represión y exterminio experimentadas en el marco de los terrorismos de Estado en el Cono Sur del continente, las llamadas ecologías violentas en Colombia ${ }^{1}$, los procesos de transición a la democracia desde dictaduras militares y las políticas de modernización neoliberal, vividas en las últimas décadas, han constituido el pasado reciente como un ámbito de estudio complejo, disputado y dinámico en América Latina. Conformado por aportes de los movimientos ciudadanos y por las aperturas investigativas críticas de las ciencias sociales, éste ha establecido el recuerdo y las memorias silenciadas por la historia como objeto de conocimiento, fuente de identidad política y de reflexión (Jelin, 2003) sobre los efectos sociales subjetivos olvidados por la historia del tiempo largo y del tiempo corto, validando la recuperación de las memorias de la represión y las violencias como un dispositivo problematizador del presente.

Esta nueva perspectiva de estudio ha abierto discusiones relacionadas con los procesos de memorialización ${ }^{2}$, los usos públicos de la historia y la subjetividad política implicada en el pasado reciente (Veles y Herrera, 2015), investigando sobre temas específicos tales como: las políticas de la memoria(Lefranc, 2004; Wilde, 2013) y la función de los sitios de memoria en la política del recuerdo (Piper, 2015), la justicia transicional y la historización de los Informes de Verdad (Jaramillo, 2009; Rubio, 2013), la transmisión intergeneracional de las memorias de la represión por los movimientos memoriales y, el carácter subjetivo y político del testimonio (Jelin, 2014; Mendoza, 2015), entre otros.

En el caso de Chile, estos estudios se han inscrito en un contexto de crisis de legitimidad del modelo de democracia llamada incompleta (Garretón y Garretón, 2010) y semisoberana (Hunneus, 2014), diseñada en el proceso de transición de la dictadura a la democracia (Mayol, 2014). La crítica ha evidenciado una alta politización de los movimientos ciudadanos que proponen el reconocimiento de las diferencias sociales y culturales como derechos y exigen una congruencia ética política a la clase gobernante (PNUD, 2015). Se cuestiona el modelo instalado desde 1990, con Pinochet aun ejerciendo como Comandante en Jefe del Ejército (1990-1996)³ que consolidó una transición

\footnotetext{
${ }^{1}$ El término se refiere a las condiciones históricas, sociales, políticas y culturales que dan cuenta de escenarios específicos de violencia que se desarrollan en Colombia que si bien, difieren de las Dictaduras del Cono sur, han planteado el estudio del pasado reciente y la memoria como parte de la formación política (Veles y Herrera, 2015).

${ }^{2}$ El término memorialización se refiere al proceso de crear memoriales públicos. Éstos son representaciones físicas o actividades conmemorativas que se relacionan con eventos del pasado y se sitúan o realizan en espacios públicos. Están diseñados para evocar una reacción o un conjunto de reacciones específicas, incluyendo un reconocimiento público del evento o de las personas representadas en él, una reflexión personal o sentimientos de duelo, orgullo, rabia o tristeza respecto de un acontecimiento pasado, así como conocimiento o curiosidad acerca de ciertos periodos en el pasado. Los Sitios de Conciencia son memoriales públicos que asumen un compromiso específico con la democracia mediante programas que estimulan el diálogo sobre temas sociales urgentes del hoy, y que aportan oportunidades para la participación pública en aquellos temas. Ver Brett y colaboradores (2007).

${ }^{3}$ Fue posteriormente, Senador Vitalicio en 1998, según la Constitución de 1980.
} 
regulada por la constitución de 1980, circunscribió la gobernabilidad a los acuerdos de los gobiernos democráticos y sus coaliciones políticas, con los partidos de derecha identificados con el pinochetismo (Lechner y Güell, 2006) y elaboró una política de la memoria del pasado reciente que reconoció la responsabilidad del Estado en la violación de derechos humanos (Informe Rettig, 1991; Informe Valech, 2004), integrando el perdón y la reconciliación como dispositivos reguladores de la cohesión social. ${ }^{*}$ El discurso político de la reconciliación tuvo un rol determinante en la definición de una memoria hegemónica que esquivó el pasado reciente y aisló las memorias sociales ${ }^{5}$, consolidando subjetividades que evidencian una débil integración de este pasado para pensar futuro (Garretón, 2003).

El modelo, fortalecería una relación disociada entre pasado reciente y el imaginario histórico social construido en democracia. Lo que unido a una retracción del Estado ante el mercado, ha consolidado una participación de los individuos en la vida social a través del consumo y de la industria financiera del crédito, en detrimento de dinámicas comunitarias y de construcción los imaginarios colectivos. Bloqueando también, las aproximaciones críticas a tal modelo, de carácter neoliberal. Se constituiría por una parte, una visión instrumental de la política y por otra, un déficit de participación ciudadana sustentadas ambas, en un discurso estructurante basado en el miedo al caos , asociado a la Unidad Popular, el miedo al castigo , instalado por la dictadura y un miedo derivativo hacia la democracia (Timmermann, 2015), en cuanto ámbito de autonomía y de apertura a nuevos actores sociales, generacionales y culturales.

Los estudios de opinión sobre el pasado reciente realizados entre 1986-2011, muestran cómo la violencia militar inesperada, la concentración del poder y el uso de mecanismos de cooptación y de preservación, unidos al uso de un lenguaje belicoso extremo utilizado por Pinochet incidieron en el déficit de cultura cívica y en una falta de entusiasmo por la democracia (Hunneus e Ibarra, 2013). Por otra parte, los estudios de transmisión de memorias (González, Manzi y Noor, 2013) evidencian la fuerte incidencia del pasado reciente en la conformación de la identidad política, fenómeno en el cual, opera una alta ideologización en la interpretación de los hechos del pasado traumático. Las identidades sociales y políticas de las nuevas generaciones, de acuerdo a su vínculo con el conflicto de dicho pasado (víctima o victimario), se relacionan con la disposición a reparar y perdonar (Carvacho et al., 2013). El trauma psicosocial de la tortura y la prisión ilegitima sigue siendo transmitido a las generaciones herederas (nietos) de las víctimas, evidenciando la permanencia de la violencia y la fisura social (Faúndez y Cornejo, 2013).

Parte de esta complejidad y de la incidencia de los procesos de transmisión de memoria en la identidad política de los jóvenes, se evidencia también con los contextos educativos, en los cuales, los adolescentes muestran una tendencia al rechazo a la dictadura y una defensa de los derechos humanos caracterizada por su desconocimiento de los hechos históricos del pasado reciente y por su incapacidad de asociarlos con el presente político (OPCIÓN-ECEN, 2013).

\footnotetext{
${ }^{4}$ Particularmente, las políticas de la memoria desarrolladas en el gobierno de Ricardo Lagos, permitirían dar una nueva imagen al Ejército en democracia, a través de la declaración Nunca más (2003). Ésta sería posteriormente cuestionada en 2016 por el procesamiento por violación de derechos humanos de su gestor, el Ex Comandante en Jefe del Ejército Juan Emilio Cheyre.

${ }^{5}$ Este discurso de la reconciliación ha sido objeto de estudio en Rubio ( 2013)
} 


\section{Dimensiones constitutivas de los movimientos memoriales}

\subsection{Trayectos y procesos de los movimientos memoriales}

La historización de la primera década (1991-2011) de los procesos de trabajo de la memoria (Jelin, 2003),muestra que las políticas de la memoria ${ }^{6}$ construidas por el Estado en consonancia con el rol activo de los movimientos de la sociedad civil que reivindican la memoria de las víctimas de las violaciones de los derechos humanos durante la dictadura, se ha constituido a partir de una sinergia conflictiva necesaria (Stern, 2013), para gestionar social y políticamente el pasado reciente, es decir, para reconocer públicamente cómo designar y explicar históricamente los acontecimientos vividos, para validar los procesos de transición y transferir una memoria pública a las generaciones futuras. Dicho trayecto, ha conformado un campo de memoria democrática de los derechos humanos, que reconoce en la memoria de consistencia ética y de defensa de los derechos humanos de fines de los ochenta ${ }^{7}$, un rol determinante en la instalación en la agenda pública del período 1991-1996 de las demandas de Verdad y Justicia en relación a las violación de los derechos humanos durante la dictadura. Esta memoria emblemática ${ }^{8}$ en democracia, logró incorporar desde una memoria testimonial; los derechos humanos y las demandas de verdad, como memoria (valor) y justicia, en las políticas de la memoria y la justicia transicional. En esta sinergia, es posible reconocer momentos de creación colaborativa (Informe Rettig, 1991) y de tensión (creación del Parque por la Paz, Villa Grimaldi, 1997)9. Así como, usos públicos del pasado y discusiones específicas de acuerdo al contexto político del presente en que emerge el recuerdo ${ }^{10}$.

Así, el año 2000, las organizaciones de ex presos políticos y de víctimas de la represión y sus familiares lograrían instalar en el debate público sobre el pasado reciente, la tortura

\footnotetext{
${ }^{6}$ Se entiende como, el marco de poder dentro del cual(o contra él) la sociedad elabora sus memorias y olvidos. La construcción colectiva de la memoria opera en una doble tensión: la relación entre pasado y futuro así como la relación entre la construcción de política y elaboración social (Lechner, 2002).

${ }^{7}$ Memoria que se oponía a la memoria como caja cerrada (Olvido) que comenzaría a instalar la dictadura desde los años 80 una vez que había decretado la ley de amnistía de 1978 como olvido consciente.

${ }^{8}$ La memoria emblemática es un marco, (...) una forma de organizar las memorias concretas y sus sentidos (...) es un marco y no un contenido concreto. Da un sentido interpretativo y un criterio concreto de selección a las memorias personales, vividas y medio-sueltas, pero no es una sola memoria, homogénea y sustantiva. (Stern, 2000, p. 14). Las memorias emblemáticas son sostenidas por grupos, que organizan su interpretación y la expresan a través de rituales y conmemoraciones públicos. El autor reconoce como memorias emblemáticas sobre el pasado reciente en Chile ; la memorias de la salvación; la memoria como ruptura no resuelta, la memoria como prueba de consecuencia ética y democrática(defensa de los derechos humanos en la década de los 80) y la memoria como olvido(resultante de la transición).

${ }^{9}$ La detención de Pinochet en Londres en 1998, abriría nuevos escenarios para las demandas de justicia y la creatividad de memoria en la sociedad civil, tales como, las Funas a torturadores que realizan hasta el día de hoy.

10 La discusión pública sobre el pasado reciente se ha abierto en distintos contextos por iniciativas políticas gubernamentales de memoria; en 1991, con el Informe Rettig, generado en la administración Aylwin (1990-1993), en torno a la verdad de la desaparición de personas y de la política de represión dictatorial; en 2004, con la elaboración del recuerdo del dolor y de la política de Campo a través del testimonio en el Informe Valech (Comisión de Verdad contra la Prisión y la Tortura Ilegitimas, convocada por el presidente Ricardo Lagos, presidida por el Obispo católico Sergio Valech). Su misión fue recoger los testimonios de las víctimas de violación de derechos humanos, en el período 1973-1990; testimonios que han sido cautelados políticamente a través de la Tesis de la guerra fría, que vendría a evitar el desborde de la experiencia de dolor en el presente, para dar estabilidad al sistema político. Para el año 2010, se convocó a una reapertura del Informe, aumentando el número de testimoniantes reparados por el Estado. Pese a no presentar una nueva tesis histórica sobre la experiencia vivida, el Museo de la Memoria y de los Derechos Humanos inaugurado en 2010 ha propiciado el contacto con un espacio testimonial público sobre la represión (1973- 1990) y desde 2015 ha generado nuevos enfoques que proyectan el trabajo de memorias en diálogo con las narrativas oficiales y las experiencias locales. En 2013, la opinión pública desde una memoria de derechos humanos integral cuestionaría las bases de legitimación de la democracia construida demandando una congruencia ética de la clase gobernante (Rubio, 2014).
} 
y la prisión política en cuanto delitos punibles penalmente que merecen reparación material y simbólica por parte del Estado, lo que sería reconocido en el Informe Final de la Comisión Valech (2004), validando tanto, el Testimonio de las víctimas y de sus familiares y a los organismos eclesiales y laicos de defensa de los derechos humanos como fuentes de verdad pública respecto a las violaciones y a la represión perpetradas por la dictadura ${ }^{11}$.

En este trayecto, el campo de memoria democrática de los derechos humanos ha asumido retos a la democracia tales como: el reconocimiento y documentación de la verdad, la apertura de caminos a la justicia penal , a través de la doctrina Aylwin (1989-1993)122, la ampliación de los trabajos de memoria sobre la prisión política y la tortura, la expansión de los sitios de memoria y la validación de la memorialización en la sociedad civil en el marco de un Estado que asume su responsabilidad en todas las esferas de su institucionalidad (1992-2006) (Lira, 2010). Desde el 2011 hasta la actualidad, el reto que se plantea es cómo transmitir la memoria del pasado reciente a las nuevas generaciones (Stern, 2013).

Desde una perspectiva centrada en las discusiones públicas sobre la memoria del pasado reciente, la experiencia chilena ha debatido sobre el aporte de la memoria a la verdad (1991-1998)13; la recuperación de la memoria republicana para fortalecer el imaginario social común(2003-2004) ${ }^{14}$; la memoria del dolor y la responsabilidad social ante la política de campo(2004); la necesidad de preservar la verdad sobre la violación de derechos humanos y la historia reciente ante las nuevas generaciones para evitar su repetición (2009-2016) democracia construida, a 40 años del golpe militar de $1973(2013-2015)^{16}$.

\subsection{Movimientos memoriales, elementos constitutivos de una nueva identidad política. Tensiones y desafios de las estrategias anamnéticas}

La memoria de las violaciones de los derechos humanos durante la dictadura ha devenido en un campo de memoria y de derechos humanos y en un movimiento social inscrito en los estudios del pasado reciente que ha generado expresiones específicas de actuación y de sentido ${ }^{17}$ evidenciadas discursivamente (contra narrativa), como performance y como razón memorial o de conmemoración (Mate, 2009; Piper,

\footnotetext{
${ }^{11}$ Las violaciones a los Derechos humanos, la tortura y la prisión ilegitima se reconocerían como hechos históricos al interior de la tesis histórica de la Guerra Fría que explicaría lo acontecido por razones externas a la sociedad y política chilena con una connotación de inevitabilidad, des responsabilizando a la clase política. Durante el año 2016 el Parlamento se negó a hacer públicas las identidades de los violadores de derechos humanos vinculados al Informe

${ }^{12}$ Los tribunales debían investigar los casos presentes en el Informe Rettig (1991) y no se aplicaría la amnistía hasta que no se estableciera la verdad y la responsabilidad.

${ }^{19}$ Es una constante que se redefine de acuerdo a los procesos de justicia y en tensión con las trampas de la memoria hegemónica.

${ }^{14}$ Con motivo de la Conmemoración de los 30 años del Golpe Militar

${ }^{15}$ La inauguración del Museo de la Memoria y de los Derechos Humanos en 2010, una institución semiprivada financiada por el Estado. Actualmente se encuentra implementando un conjunto de innovaciones pedagógicas para el trabajo de memoria y de los derechos humanos que involucra una relación activa presente/ pasado que abre la memoria hegemónica que mandata su misión al dialogo crítico.

${ }^{16}$ Desde la conmemoración de los 40 años del Golpe Militar, en el marco de una crisis de la democracia establecida, la memoria social de la opinión pública ha cuestionado la representatividad y calidad ética de los gobernantes como resultante de la transición.

${ }^{17}$ Los testimonios y relatos de la violencia del exilio, de la resistencia a las dictadura, los informes oficiales de Verdad y Reparación, las demandas y los procesos judiciales para sancionar a los violadores de derechos humanos, las iniciativas de los familiares de las víctimas y de los propios afectados para rescatar la memoria digna de los reprimidos, la creación de sitios memoriales y la implementación de proyectos de pedagogía de la memoria.
} 
Fernández, Iñiguez-Rueda, 2013). Podemos hablar de un círculo de sentido-acción de los movimientos memoriales que se manifiesta a través de narrativas conmemorativas y de denuncia de las violaciones de los derechos humanos en la dictadura configuradas como rituales domésticos, territoriales y políticos, que adquieren formas dramáticas, pedagógicas y de intervención en espacios públicos, a través de sitios de memoria y recintos de documentación .

Estos últimos, conformados por entidades formales vinculadas a organizaciones históricas de derechos humanos, de la iglesia católica o bien de dependencia pública, asignan a la documentación recabada el atributo de recurso moral y de rescate de todo el olvido institucionalizado (Piper, Fernández, Iñiguez-Rueda, 2013). Mate (2009) considera a este complejo del recuerdo, portador de un contenido moral y político, como un componente y eje articulador de conciencia, en una pedagogía del caído sustentada en lo narrativo y lo experiencial.

El Testimonio que adjetivamos como testimonio memorial, no es considerado como un acto espontáneo o naif, sino como un acción estructurada en torno a una estrategia de la palabra del/de la testigo/a; una estrategia annamética ${ }^{18}$ (Mate, 2009) que posee dos dimensiones: la recuperación del recuerdo de las víctimas desaparecidas vía familiares y segundas y terceras generaciones (Sepúlveda et al., 2015), y la demanda por la justicia en cuanto reparación y dispositivo que asegura en el tiempo que la memoria de las violaciones de los derechos humanos no sea nunca excluida ni olvidada del debate público. El mismo Mate plantea que el trabajo de la memoria no constituye una nueva ideología de los movimientos sociales sino una categoría de una nueva modernidad, de una novedad que cuestiona el sentido progresista de un capitalismo productor de escombros y cadáveres (Mate, 2009).

$\mathrm{Al}$ interior del campo de memoria democrática y de los derechos humanos antes descrito, las organizaciones de Derechos Humanos y de los familiares de las víctimas han aportado una razón práctica memorial configurada en un contexto de deliberación y disputas con las entidades que han gestionado en la transición democrática, las políticas de memoria, verdad, justicia, reparación y educación. A nuestro entender, la razón práctica memorial, de este movimiento se ha constituido a partir de una dimensión experiencial e histórica, en la cual se ha sustentado su participación en la vida política post dictadura. Esta reconoce como núcleo basal, la experiencia traumática del sufrimiento y sus producciones narrativas identitarias a partir de las violaciones de derechos humanos y de la represión. Las experiencias del horror de la violencia y de la represión constituyen una reserva de memoria vivida y base del principio de resistencia, la denuncia y combate a una cultura de terror que provoca desapariciones, ejecuciones destierros, inseguridad radical, separaciones familiares, despojos patrimoniales y persecuciones culturales. En dicha experiencia, la constitución de círculos de solidaridad entre las víctimas, sus familiares y agentes de apoyo (las iglesias, grupos de abogados y médicos, por ejemplo) constituyen el núcleo activo y protector del movimiento.

\footnotetext{
${ }^{18} \mathrm{El}$ concepto estrategias anamnéticas se refiere a las operaciones y dispositivos políticos , culturales y pedagógicos destinados a validar el recuerdo, la conmemoración y la reparación material y simbólica de las violaciones de los derechos humanos de grupos sociales, políticos, étnicos o lingüísticos por la acción de regímenes totalitarios y las prácticas del terrorismo de Estado (como el que practicaron las dictaduras militares del Cono Sur de América Latina) en cuanto principios fundantes de la ética democrática.
} 
A inicios de los años 90 del siglo pasado, el movimiento se conformaría como un actor crítico en la transición democrática post dictadura poniendo en cuestión el concepto de Reconciliación en cuanto proceso de transacción que garantizase lo que las nuevas autoridades llamaron; la gobernabilidad y la justicia en la medida de lo posible, lo que se manifestó ante los trabajos tanto en la Comisión Rettig como de la Comisión Valech ${ }^{19}$ con un repertorio de propuestas que los identificaría como actores políticos claves en la discusión sobre políticas de la memoria en la transición política post 1990.

Por su parte, la dimensión política democrática, se orienta a abrir la democracia constituida hacia nuevas discusiones y nuevos derechos que, considerando el vínculo traumático con el pasado reciente, se ordenan a desarrollar una apertura del pensamiento político integrando el testimonio como prueba de violación de derechos humanos junto con la demanda de espacios de resguardo (archivos), de transmisión y de enseñanza del pasado reciente para contribuir a generar ciudadanías complejas que desarrollen capacidades memoriales y políticas para defender la democracia y los derechos humanos.

Esta dimensión se configura a partir de:

- Acción anamnética configura a través de diversos dispositivos y lenguajes que se expresan a través de; la generación de circuitos y espacios de verbalización del impacto emocional, político, penal y laboral de la represión, usando medios de comunicación alternativos, centros culturales y, la expresión dramatúrgica y plástica.

- Ampliación de las denuncias y de las resistencias al olvido. La generación y participación en alianzas y plataformas de lucha política plurales, relevando en ellas, las demandas y consignas tales como el Nunca más, Justicia, Verdad y Reparación, o Ni perdón ni olvido.

- Politización del relato de verdad de las Comisiones Oficiales, haciéndose parte de una dinámica ético-crítica sobre las bases pactadas de la transición democrática (Méndez, 2006).

- Expansión de su campo de incidencia pública al ámbito de la cultura, la opinión pública y las artes a través de acciones educativas, artísticas y de recuperación de las memorias históricas de los reprimidos, las víctimas y, la re-significación del núcleo existencial primero, el movimiento memorial (sufrimiento) vía proceso de recuperación, escritura y empoderamiento simbólico de las memorias históricas subalternas, cuestionando la normalidad historiográfica ${ }^{20}$.

El sujeto del movimiento memorial activa memorias sentí-pensadas desde el presente que resignifican el pasado en el devenir de la realidad concreta. En esta perspectiva el pasado no pasa, al pasado se lo re-visita, se le actualiza, e interroga para comprender con mayor profundidad y amplitud lo que nos ocurre, mientras está ocurriendo aquí y ahora, para desde allí, imaginar futuros posibles (Quintar, 2015). Incide en la generación de proyectos más o menos institucionalizados de educación para la defensa y promoción de los derechos humanos y participa en las disputas sobre el sentido de la enseñanza de la

\footnotetext{
${ }^{19}$ Para un análisis del discurso de la Reconciliación en ambas Comisiones ver Rubio (2013).

${ }^{20}$ Un estudio de estas diversas manifestaciones en Chile y Uruguay en Zaliasnick, 2016.
} 
historia reciente en el currículo del sistema nacional de educación y en la experiencia de dialogías intergeneracionales de memoria (Reyes, Cruz y Aguirre, 2016; Reyes et al., 2014; Sepúlveda et al., 2015) que se manifiestan en programas de educación y de actualización del significado ético de las violaciones de los derechos humanos, así como la acciones referidas a su defensa durante la dictadura. Inscribiendo, a través de estas acciones, la recuperación de las memorias y la lucha por la verdad y la justicia en un conjunto de desafíos comunes inter-etarios de la democracia.

2.2.1. Los movimientos memoriales y el campo de la memoria. Tensiones con la narrativa historiográfica y desafios en educación

Los procesos de memorialización activa y de trabajo de memoria promovidos por el Estado y los movimientos memoriales (Brett et al., 2007; Collins y Hite, 2013; Feld y Garaño, 2014) han contribuido también, a tensionar lo marcos tradicionales de la investigación histórica, situándola en el marco de una cultura histórica (Sánchez Marcos, 2009) que debate sobre los pasados, sus silencios, los deseos y las expectativas de futuro, en la cual, la investigación del pasado reciente se inscribe como una práctica específica, sujeta a ciertas reglas y regímenes de historicidad (Mudrovic, 2014).

Los fenómenos de identificación política asociados al recuerdo y la continuidad entre la narración y la experiencia temporal, tensionan la relación entre el discurso histórico, la memoria social y el contexto sociopolítico en que se genera el recuerdo, abriendo discusiones sobre; el valor de la verdad, la neutralidad valorativa del hecho analizado y el carácter ético y político del relato (Mudrovic, 2005).

Esto implica situarse en el marco de los estudios sobre los discursos sobre el pasado reciente, entendiendo éstos como una producción social del presente que exige pensar el poder implícito en los usos del pasado ${ }^{21}$. Por ello, ante el pasado reciente no es posible sostener una ingenuidad epistemológica sobre la correspondencia univoca entre narración histórica y el hecho narrado, más bien, conviene abrir la discusión, por una parte; sobre la incidencia de contextos y subjetividades (memorias) en la construcción y la circulación social del recuerdo y, por otra; sobre la relación entre conocimiento, subjetividad y política (Cuesta, 2015).

Otros puntos que tensionan a la investigación historiográfica tradicional y las narrativas históricas explicativas son; el carácter inacabado de los fenómenos estudiados, la implicación generacional de los investigadores con el objeto investigado, la inscripción de la narrativa y de la operación historiográfica (de Certeau, citado en Ricoeur, 2004) en la discusión por la verdad y el uso de conceptualizaciones y metodologías provenientes, de las ciencias jurídicas y del paradigma de los derechos humanos y del Holocausto (Traverso, 2011). A ello se agrega, la tensión a la explicación histórica neutral, por el uso de las categorías del testigo, el testimonio, el horror, las víctimas, la memoria viva y el deber de la memoria que abren dicha función a posiciones éticas y narrativas específicas (Mate, 2006; Mélich, 2004; Ruiz Torres, 2007)22.

\footnotetext{
${ }^{21}$ Que ha abierto investigaciones sobre las historias de las disputas por la memoria (Mendoza, 2015).

${ }_{22} \mathrm{El}$ discurso historiográfico en nuestro país, no ha establecido un marco conceptual común o onvergente para abordar el pasado reciente, debido principalmente a la fuerza de los enfoques que sustentan las premisas de objetividad y distancia para la investigación. Sin embargo, la relación de algunos historiadores con la historia oral anglosajona, con los movimientos de derechos humanos y las víctimas $\mathrm{y}$, su compromiso con la memoria social de los excluidos y perseguidos, ha abierto argumentos para la ruptura epistemológica, desde la historia oral y la memoria, como reverso y crítica de la historia oficial dictatorial (Garcés y Leiva, 2005).
} 
Las narrativas y acciones de los movimientos de memoria representan un proyecto de interpretación histórica de las dictaduras y del período posterior de la democracia que ha integrado diversos dispositivos para la activación del recuerdo y la reflexión sobre los usos públicos del pasado tales como; archivos y registros orales y audiovisuales; fondos documentales de los procesos judiciales; repertorios de testimonios difundidos en formatos plurales ${ }^{23}$; sitios memoriales; museos y bibliotecas públicas; proyectos educativos comunitarios y escolares; intervenciones de espacios públicos; dramaturgia y plástica.

En dicho trayecto, basándose en la memoria como dispositivo dinamizador del recuerdo, se han confrontado diversas narrativas históricas en diálogo crítico con los relatos hegemónicos, cuestionando en primer lugar; el orden temporal secuencial y evolucionista de la narrativa hegemónica presente en el curriculum escolar, que establece una continuidad histórica necesaria, por una parte entre; la llamada crisis de la Unidad Popular y el Golpe de Estado de 1973, proceso explicado por la tesis histórica de la Guerra Fría y por otra, entre; la Dictadura y violación de derechos humanos (19731989) y el retorno a la democracia en 1990, proceso explicado por la necesidad de defensa de los derechos humanos y la democracia ${ }^{24}$. La disputa en las generaciones actuales por la explicación de lo acontecido en torno a estos hitos históricos es evadida por la memoria hegemónica a través de la estrategia de la indagación histórica y del uso de testimonios (como fuente de información). El supuesto es que la indagación que deben realizar los estudiantes,- sin considerar sus propias memorias-, permitirá acceder a la explicación histórica local de lo acontecido ${ }^{25}$.

Las tesis explicativas sobre el gobierno de la Unidad Popular, su crisis, el golpe militar y la instalación de la dictadura, no tienen relación con los hitos de dictadura y violación de derechos humanos y de recuperación de la democracia y no dan cuenta de la implicación y responsabilidad de la clase política. Por su parte, la razón práctica memorial, desarrolla propuestas de narrativas históricas que rompen con la continuidad necesaria de los hechos del relato hegemónico, abriendo análisis e interpretaciones genealógicas(principalmente entre los intelectuales)que dan cuenta de las disputas de poder desarrolladas al interior de la clase política para ordenar la transición pactada (Moulián, 1998) y, de las formas de configuración del marco neoliberal de la democracia (Cárcamo-Huechante, 2007), relevando cómo los sectores pinochetistas fueron abandonando su discurso patriótico introduciendo uno mercantil democrático. Evidenciando ambos, la configuración del presente como un proceso que no formaba parte de una evolución natural del pasado reciente sino que fue resultado de una disputa y un trastrocamiento de referentes políticos y sociales. Por su parte, Richard (2010) desde una crítica de la memoria que supone la posibilidad de anudar prácticas y

\footnotetext{
.${ }^{23}$ Videos, libros, portales en la web, blogs, audio- archivos, entro otros. Se puede acceder a ellos en : www.museodelamemoria.cl

${ }^{24}$ Estos hitos históricos se encuentran presentes en el currículo para la enseñanza de la historia reciente en tercer año medio y no tienen continuidad explicativa entre sí. La tesis de la Guerra Fría, actúa como marco explicativo global de la historia y sus efectos, a ella se unen; la tesis de la Decadencia de la República y el Determinismo histórico, que ordenan las coyunturas políticas inmediatas al golpe de estado de 1973. Todas consolidan unas memorias Hegemónicas que orientan una pedagogía de sentido de la experiencia social que evade la reflexión de los hechos históricos, asume tácitamente la imposición del perdón y promueve una memoria ingenua que no se apropia de la existencia histórica de la violación de derechos humanos como expresiones de la Política de campo instalada en la dictadura militar (1973-1990).Ver Rubio,2013a

25 El curriculum propone investigar las posiciones historiográficas opuestas como una estrategia para explicar lo acontecido. Sin aportar elementos de juicio para el análisis crítico.
} 
escenarios de actuación normalmente parcelados en disciplinas académicas diversas, reflexiona sobre la exposición de la memoria social a las inversiones, conversiones y reversiones del presente ${ }^{26}$ y sobre cómo la retórica del pasado reciente (retoricas, escenas y lenguajes figurativos) de la postdicatadura han rondado sobre la ausencia y carencias de lo que falta ${ }^{27}$.

Desde los movimientos memoriales, diversas organizaciones han comenzado a vincularse con escuelas para transmitir vía testimonio, la narrativa de la represión, la prisión y la tortura como fragmentos de la historia vivida, enfatizando la experiencia de la víctima en sus dimensiones políticas, sociales y culturales ${ }^{28}$. Muchas de ellas son historias no conocidas y no integradas en las memorias hegemónicas y emblemáticas ${ }^{29}$. Los relatos dan cuenta de aspectos humanos situados que vitalizan no sin riesgo ${ }^{30}$, el vínculo intergeneracional con lo indecible de la transmisión del recuerdo y desafían a la comprensión, a integrarlo como aprendizaje y diálogo con el relato histórico oficial ${ }^{31}$. A través del testimonio, se han puesto en escena a aquellos sujetos que han sido silenciados; mujeres prisioneras en juventud (Calderón y Gutiérrez, 2011), Ex Niños y organizaciones territoriales de víctimas de violaciones de derechos humanos ${ }^{32}$.

La narrativa testimonial puede articularse con diversas estrategias, tales como la narración directa de quien ha vivido la violación de derechos humanos y comunicando la profundidad de la violencia en el cuerpo que marcó la vida de una generación. Pueden presentarse mediadas por dispositivos (libros, documentales, exposiciones plásticas y fotográficas, obras teatrales), que permiten por una parte; desarrollar una recreación de lo vivido y de los hechos históricos, y por otra; testimoniar en un sitio de memoria, en donde reside la huella del dolor y la reserva de historia de represión ${ }^{33}$.

Estas aproximaciones como posibilidad del presente que revisita el pasado desde lo vivido, rompen la continuidad de la memoria hegemónica, relativizan la fuerza de las tesis históricas explicativas y abren la historia disponible a la experiencia humana y a la responsabilidad política por lo acontecido. Por su parte, la post memoria (Hirsch, 2008) también abre nuevos relatos de memoria de quienes han sido los herederos de los desaparecidos y afectados, los que vienen a presentar sus visiones históricas resultantes

\footnotetext{
${ }^{26}$ En 2010asumió el gobierno una coalición política de derecha y presidido por Sebastián Piñera, quien se apoderó del concepto de desaparecidos que identificaba a los ciudadanos asesinados y desaparecidos por acción de la dictadura y a sus familiares que habían luchado por la defensa de los derechos humanos, usándolo para designar a los muertos desaparecidos en el terremoto y tsunami que afectó al país, siendo presentado ahora como símbolos de lo que debería ser la unidad de la nación en torno a las políticas de reconstrucción de las zonas afectadas emprendidas por el nuevo gobierno.

${ }^{27}$ Lo que falta, se refiere a todo lo restado, cuerpos, existencias e ideologías que fueron anulados por las pasiones dela historia (Richard, 2010).

${ }^{28} \mathrm{El}$ testimonio puede entenderse como fuente de conocimiento y de acercamiento a lo indecible y a la resignificación de la experiencia de violación de derechos humanos (Bárcena, 2011).

29 Ver www.facebook.com/latidosdelamemoria, https://www.facebook.com/groups/HIJXSMEMORIA/?fref=ts; http://www.memoriaviva.com/

so Estas iniciativas son emergentes en nuestro país y se realizan movidas por la necesidad de testimoniar. Se requieren sean atendidas cuidadosamente tanto por el valor de lo narrado como por la responsabilidad ante quien realiza el testimonio expresado ante herederos/as no siempre preparados para la escucha.

${ }^{31} \mathrm{El}$ acto de testimoniar ante las nuevas generaciones no asegura aprendizaje del pasado reciente. El acto de testimoniar debe ser un acto cuidado y abierto al reconocimiento del otro.

${ }^{32}$ Ver http://www.centroexil.org/programas/8-asociacion_exil_chile

${ }^{3}$ El Gobierno de Michelle Bachelet evidenció la mayor expansión de iniciativas de memoria con la sociedad civil. Los memoriales llegarían a 160 en 2010 según Wilde y sobre 200 en 2014, según Collins y Hite (2013) http://villagrimaldi.cl/, http://tumemorial.cl/, http://www.londres38.cl/1937/w3-channel.html
} 
de la transmisión fragmentada de lo acontecido ${ }^{34}$. También, las narrativas militantes y críticas, integran el presente cuestionado como dispositivo dinamizador y problematizador del recuerdo, tensionando la relación con el pasado y con el futuro. Al respecto, las narrativas del sitio memorial Londres 38 aportan a la discusión de la violación de derechos humanos tanto en el pasado reciente como en el presente y validan los proyectos de justicia en marcha, que fueron derrotados, pero no vencidos en el pasado reciente ${ }^{35}$.

También, se ha tensionado el uso del archivo tradicional y la relación del investigador con las fuentes históricas. La constitución de los archivos de la represión es reciente ${ }^{36}$, los-as investigadores-as deben superar las tendencias a la dispersión por el paso del tiempo y del silencio y ocultamiento de los hechos acumulado. Por otra parte, el acceso a la experiencia de violación de derechos que forma parte de los hechos de represión dictatorial, está mediada por las posibilidades de la transmisión y representación de lo indecible (Faúndez, Cornejo y Brackelaire, 2013). Esa zona indescifrada pero existente de dicha experiencia, plantea una problematización mayor respecto del carácter del conocimiento que compone la narrativa histórica del pasado reciente y de las posibilidades y estrategias para poder pensarlo para su transmisión.

En suma, las estrategias anamnéticas han integrado una nueva expresión del pasado reciente que revierte el poder de la cultura escrituraria ${ }^{37}$ definida para la transmisión y como veremos para el aprendizaje histórico, abriéndola a lenguajes figurativos y estéticos, los cuales, mueven diálogos activos entre presente y pasado; recuperan memorias de la historia del tiempo largo y las inscriben en el tiempo corto, conformando una política identitaria manifiesta como movimiento social particular que puede ser visto como apuesta de construcción de representaciones historiográficas del pasado reciente ${ }^{38}$.

Por su parte, los desafíos educativos se relacionan con definir qué aprendizajes se deben propiciar a partir de las experiencias ancladas al pasado reciente. Existe un consenso en

${ }^{34}$ La Historia de un Oso, cortometraje chileno ganador de un Oscar en 2016. Narra la historia de la prisión, el dolor y el exilio de un ex dirigente de la Unidad Popular vista por su nieto (heredero) que representa estética y emotivamente la experiencia.

${ }^{35}$ Las apuestas de proyección de la violación de derechos humanos en el presente requieren espacial atención sobre sobre quienes asisten a su presentación, (quienes vivieron y las generaciones que heredaron dicho pasado) para $\mathrm{r}^{35}$ Lo que falta, se refiere a todo lo restado , cuerpos, existencias e ideologías que fueron anulados por las pasiones dela historia (Richard, $2010)$.

${ }^{35} \mathrm{El}$ testimonio puede entenderse como fuente de conocimiento y de acercamiento a lo indecible y a la resignificación de la experiencia de violación de derechos humanos (Bárcena, 2011).

s5 Ver www.facebook.com/latidosdelamemoria, https://www.facebook.com/groups/HIJXSMEMORIA/?fref=ts; http://www.memoriaviva.com/

${ }^{35}$ Estas iniciativas son emergentes en nuestro país y se realizan movidas por la necesidad de testimoniar. Se requieren sean atendidas cuidadosamente tanto por el valor de lo narrado como por la responsabilidad ante quien realiza el testimonio expresado ante herederos/as no siempre preparados para la escucha

${ }^{35} \mathrm{El}$ acto de testimoniar ante las nuevas generaciones no asegura aprendizaje del pasado reciente. El acto de testimoniar debe ser un acto cuidado y abierto al reconocimiento del otro.

35 Ver http://www.centroexil.org/programas/8-asociacion_exil_chile

${ }^{35}$ Se debe resguardar la diferenciación y delimitación de las continuidades y discontinuidades históricas que se pretenden transmitir y discutir. Del mismo modo, la transmisión del miedo es un punto a ser reflexionado en términos de los propósitos pedagógicos implicados en su desarrollo.

${ }^{36}$ Sobre archivos y memoria de la represión durante las dictaduras latinoamericanas ver Acuña et al. (2016).

${ }^{37}$ Los movimientos de la memoria pueden ser pensados siguiendo a Rama (2004) en la ciudad letrada , como una nueva forma de cultura contestataria a los dictámenes de la escrituraria de la historia y desarrollan a través de los sitios, memoriales y lugares, una nueva significación inaugurando nuevos recorridos en las ciudades latinoamericanas.

s8 Sobre la producción de relatos como dispositivo constituyente de los movimientos memoriales ver Gaborit (2006), Montealegre (2013) 
valorar una educación ciudadana fundada axialmente en los derechos humanos (Osorio, 2016), sin embargo, este eje no agota los aprendizajes, puesto que según lo que hemos señalado anteriormente, la razón práctica memorial también, incorpora la dimensión histórica como un eje de memoria/historia activo para pensar el presente y el futuro. Esta multidimensionalidad del uso público del pasado exige pensar apuestas pedagógicas que integren perspectivas de la historia, la memoria social y los derechos humanos así como reflexionar sobre sus tensiones para su proyección en la enseñanza. Uno de los puntos de tensión dice relación con pensar el testimonio desde el aprendizaje. Designado como conocimiento imposible (Bárcena, 2011) desafía particularmente a los presupuestos éticos de la educación, exigiendo diferenciar, lo indecible de un acontecimiento como experiencia vivida por un testigo/a, de asumir lo indecible como dogma impuesto por un discurso externo a la experiencia vivida. (Huberman, 2003 citado en Bárcena, 2011).

Presentamos a continuación algunos principios de base sobre como pensar la historia como acontecer, su relación con la memoria y los derechos humanos para propiciar la enseñanza del pasado reciente ${ }^{39}$.

El pasado reciente nos plantea la necesidad de pensar la historia desde otro lugar, esto implica asumir la condición histórica desde la responsabilidad, evidenciando cómo los hechos, experiencias y herencias del tiempo corto y largo se transforman en un desafío para la comprensión y la reflexión política en la que el sujeto asume un rol activo. (Cuesta, 2011) Ese desafío exige integrar memoria e historia ${ }^{40}$ como sustento de una ciudadanía responsable de su pasado y su futuro, basada en el derecho a tener derechos, como una condición en permanente expansión (Arendt, 1973, citado en Jelin, 2003) en donde el pasado se transforma en un recurso para la confrontación del presente y el futuro.

Esto nos exige asumir los siguientes principios de base para pensar la historia en relación con el sujeto; el primero, es que ésta (como acontecer relatado) no está disponible (Kosseleck, 1994). Desde la perspectiva de las experiencia del horror, no se asegura (per se) su recuperación, narración y su transmisión. Del mismo modo, la producción de los relatos y las investigaciones tampoco asegura su disponibilidad, se requieren de sujetos habilitados para su comprensión y aprendizaje. Lo que supone una activación permanente del recuerdo y la responsabilidad como capacidad de pensamiento histórico. El segundo principio dice relación con la condición de herencia y construcción histórica en la que se inscribe el sujeto. Heredamos historias construidas por otros que nos ponen en disyuntivas más o menos complejas y a la vez, construimos o nos inscribimos en las posibilidades de construcción de nuevas historias (Mélich, 2004). Es allí donde, la razón práctica memorial (memoria como capacidad reflexiva) puede activar procesos de diálogo crítico entre el fondo de experiencia (lo acontecido) y el horizonte de espera (futuros posibles) pensados desde el presente $^{41}$. El fondo de experiencia se

\footnotetext{
${ }^{39}$ Principios de base para pensar la historia que emergen de la reflexión ética, política y epistemológica de los pasados violentos que han interpelado a la historia reciente tanto en Europa con motivo de pasados de violentos así como en contextos post transicionales y de violencia en América Latina. Ello demanda pensar la historia integrando la subjetividad y las memorias como dispositivos para la formación de capacidades para el pensamiento histórico como sustento de la formación política a desarrollar en contextos educativos escolares y otros escenarios de la sociedad civil.

${ }^{40}$ La genealogía evidencia que historia y memoria fueron concebidas históricamente unidas, y que su disociación es un episodio marcado por un trayecto disciplinar específico (Cuesta, 2014).

${ }^{41}$ A propósito del presente complejo que trae a los vencidos (su memoria) ver Benjamin, citado en Mate (2006) y Ricoeur (2004).
} 
transforma por la razón práctica memorial, en un pasado abierto, que puede ser cepillado a contrapelo (Cuesta, 2011), que exige como condición de una ciudadanía memorial, por una parte; ser abierto con nuevas preguntas (Tocornal, 2010) y por otra, ser pensado/recordado desde el otro en dicha historia, abriendo nuevas memorias que ponen en tensión las identidades sociales y políticas establecidas.

Por otra parte, el análisis del recorrido histórico de la razón práctica memorial en relación al aprendizaje posible de los pasados recientes, da cuenta de los principios que se deben considerar para formar una ciudadanía de nuevo tipo, es decir, memorial ${ }^{42}$.

Comprender la historia a partir de los efectos de la historia reciente. Esto orienta qué y cómo recordar. El pasado reciente ha generado efectos diferenciados en nuestra sociedad expresada como; víctimas, allegados, herederos, colaboradores, cómplices pasivos, procesos transgeneracionales de memoria y comunidades de sentido futuras. Deben considerarse en relación a la definición de los hechos históricos que pretendemos relevar para articular la relación entre memoria e historia y potenciar la comprensión histórica. Preguntándonos sobre cual memoria integramos para evocar el pasado; para legitimar o cuestionar el presente?

Considerar las determinaciones de posición económica y social frente al pasado reciente. Cada trayectoria del pasado inscribe una determinación de posición histórica (Giroux, 2003) que incide en la narrativa de ese pasado, que se expresa a través de las memorias emblemáticas (Stern, 2000) y sociales. Las determinaciones aportan a la comprensión de experiencias disímiles vividas y heredadas para iniciar el trabajo de la memoria.

Reconocer la enseñanza como un espacio para la creación de una comunidad de sentido. La enseñanza del recuerdo debe orientarse pensando en el futuro y en la formación ciudadana (Bárcena, 2011). Ello define el compromiso explícito de esta enseñanza para la formación de ciudadanos responsables que asumen los derechos humanos.

Problematizar la historia y el recuerdo. Definir algunos núcleos problemáticos prioritarios para la enseñanza. Desde nuestra experiencia concentracionaria basada en la pedagogía pública del miedo (Rubio, 2013), emergen algunos núcleos que deben ser pensados desde los derechos humanos, y que exigen a la vez, evitar la pedagogización del recuerdo, esto es, reproducir relatos ejemplares sin abrirlos a dialogo (Bárcena, 2011) así como, activar procesos de des-memorialización (Sacavino, 2015). Entre los núcleos problemáticos a trabajar encontramos; el quiebre de la vida republicana; la vulneración histórica de derechos de la mujer y de los niños; cuestionar las herencias y las posibilidades fácticas de construcción de la institucionalidad republicana; cómo superar la linealidad y continuidad como ordenadores del relato histórico. El daño y dolor del cuerpo y la ciudadanía vulnerada; la demanda de aprender la convivencia política como el cuidado del otro y problematizar la experiencia heredada desde la responsabilidad ante el futuro. Una característica del pensamiento histórico memorial comprometido con la defensa de los derechos humanos es la promoción de una actitud crítica constante sobre el recuerdo y su activación que evite que éste se hegemonice y transforme en memoria oficial deshumanizada.

${ }^{42}$ La crítica supone debatir sobre los principios que han ordenado la investigación histórica y su rol en la constitución del recuerdo del pasado reciente. Abrir diálogo desde el presente hacia el pasado activando, memoria e historia.(Rubio, 2016) 
Se trata de abrir un régimen de memoria (Crenzel, 2008) dinámico y complejo que permita fortalecer capacidades ciudadanas que se vinculen con la historia desde una perspectiva crítica que recuerde y piense el acontecer histórico integrando los derechos humanos como referencia analítica. Por último, desde esta razón práctica memorial es posible reconocer capacidades ciudadanas que se transforman en un activo para la ciudadanía memorial. Entre éstas podemos reconocer las siguientes:

\begin{abstract}
Ciudadanía que asume su condición histórica. Es heredera del pasado reciente y piensa futuro.

Ciudadanía que se siente parte de una comunidad de sentido. Sensible, abierta al otro en el presente y en el pasado.

Ciudadanía que asume los derechos humanos como referencia para pensar la historia. Con una memoria que reflexiona sobre el sentido de la violación de derechos humanos.

Ciudadanía que piensa la historia política del pasado reciente. Conoce y comprende los proyectos políticos que no llegaron a concretarse.

Ciudadanía activa con conciencia histórica. Con una memoria crítica de los relatos oficiales y con una conciencia histórica (se piensa con otros temporalmente) que vincula presente y pasado para pensar futuros como acción del presente. (Rubio, 2016)
\end{abstract}

Podemos concluir que los movimientos memoriales reivindican una política que podemos definir como de reconocimiento, esto es una política constituida desde un sentido de comunidad y reciprocidad que representa y demanda a la sociedad el reconocimiento de formas morales que se consideran sustantivas para la democracia y que deben incorporarse a través de tres vías: la normativa-legal; la comunicacional, creándose instituciones que permitan conmemorar y educar en los derechos humanos, y; la educativa, que demanda al poder político la generación de una cultura política a través de su sistema nacional de educación en todas las modalidades y niveles etarios de éste. Estas tres dimensiones constituyen una ciudadanía memorial, es decir el atributo siempre perfectible de la democracia para desarrollar capacidades jurídicas, culturales y educacionales que permitan que la conmemoración se identifique con el sentido mismo de la vida en común.

En suma, el desarrollo de una razón ciudadana memorial contribuye a configurar una democracia de nuevo tipo, que integre la justicia en las memorias (Mendoza, 2015). Este enfoque de ciudadanía de los movimientos memoriales ha tensionado las narrativas históricas oficiales presentes en diversos escenarios y dispositivos de la institucionalidad política, al mismo tiempo, que ha planteado desafíos educativos en torno a qué, cómo y para qué enseñar el pasado reciente, lo que ha interpelado a su vez, cuestionamientos disciplinares y pedagógicos cuando se incorpora la memoria como dispositivo reflexivo educativo (Rubio, 2013).

\title{
3. Conclusiones
}

Los movimientos que han actuado para recuperar la memoria histórica relacionada con la violación de los derechos humanos durante la dictadura aspiran contribuir a la reparación de una sociedad herida. Aspecto clave de la política identitaria del movimiento memorial es su relación con el trauma, con el sufrimiento y la violación de derechos humanos. En un proceso de politización del trauma, su estrategia de incidencia 
pública se relaciona con satisfacer la necesidad humana de reconstruir proyectos de vida en condiciones de paz y no de terror o miedos institucionalizados como en la dictadura. El movimiento memorial sitúa su posición identitaria desde una ética de responsabilidad pública. Lo que plantea un tema de gran grosor, ¿cuál es el del sentido que tiene este responder en los movimientos memoriales? ¿Responde la historiografía? ¿Responde la sociedad? ¿O el diluido sentido ético de la sociedad hará que sólo las víctimas hablen por todos los demás? La responsabilidad frente a la historia implica también una capacidad de dar cuenta, es decir el reconocimiento de la dimensión problemática del pasado. Cuando esa responsabilidad se diluye, se nos devuelve una dimensión estetizante del pasado, un estado de vaciamiento crítico. Asumimos representaciones del pasado que no nos afectan, representaciones sin marcos reflexivos que nos involucren. Al sustraer la responsabilidad de lo histórico, esa representación nos lleva a un lugar de tránsito, a una escena que puede ser contemplada pero no admite intervención alguna, en el sentido epistémico, en la intención de conocerla (Gentile, 2015).

El movimiento memorial se empodera desde sus procesos identitarios en cuanto produce una contra-narrativa que pretende darle nuevos sentidos al pasado reciente, a enmarcar la historia reciente como historia infausta, por tanto es un narrativa liberadora, que se constituye desde la voz de los-as ciudadanos-as vulnerados-as y de sus archivos que son definidos como fuente primaria por su eticidad y no solo por las reglas epistémicas de la historiografía tradicional.

En dicho trayecto, se define como conciencia ética, conmemorativa de la violación de derechos humanos (conmemorar: hacer memorias juntos) y como tal, se exploran formas de expresión, rituales, intervenciones de espacios públicos que ofrecen al ciudadano-a otras formas de aprender y leer historia en diálogo crítico con las formas canónicas de enseñar y estudiar la historia reciente, a través de: lugares memoriales, peregrinaciones, intervenciones forenses, educación intergeneracional. Es importante destacar que las manifestaciones del movimiento memorial no son mera recuperación de voces de los de abajo sino que manifiestan itinerarios conceptuales que plantean que hay diversas formas de hablar-narrar y representar el pasado reciente: no hay un monopolio de la historia disciplinar para hablar con sentido del pasado.

\section{Referencias}

Acuña, M, Flier, P., González, M, Groppo, B., Hevia, E., López, L. ... y Traverso, E. (2016). Archivos y memoria de la represión en América Latina (1973-1990). Santiago: LOM

Balibar, E. (2013). Ciudadanía. Buenos Aires: Adriana Hidalgo Editora.

Bárcena, F. (2011). Pedagogía de la memoria y transmisión del mundo. Notas para una reflexión. Revista Con-ciencia Social, 15, 109-118.

Brett, S, Bickford, L. Sevcencko, L y Ríos, M. (2007). Memorialización y democracia. Políticas de estado y acción civil. Santiago: Flacso.

Calderón, A. y Gutiérrez, R. (2011). Éramos liceanas en septiembre de 1973. Santiago: Planeta de Papel.

Cárcamo-Huechante, L. (2007). Las tramas del mercado. Imaginación económica, cultura pública y literatura en el Chile de fines del siglo XX. Santiago: Cuarto Propio. 
Carvacho, H., Manzi, J., Haye, A., González, R., Cornejo, M. (2013). Consenso y disenso en la memoria histórica y en las actitudes hacia la reparación en tres generaciones de chilenos. Psykhe, 22(2)33-47. doi: 10.7764/psykhe.22.2.601

Collins C. e Hite, K. (2013). Fragmentos de memoriales, silencios monumentales y despertares en el Chile del siglo XXI. En K. Collins, K. y A. Joignant (Eds.), Las políticas de la memoria en Chile: Desde Pinochet a Bachelet (pp. 161-192). Santiago: Ediciones Universidad Diego Portales.

Crenzel, E. (2008). La historia política del nunca más. La memoria de las desapariciones en la Argentina. Buenos Aires: Siglo XXI.

Cuesta, R. (2011) Historia con memoria. Revista Con-Ciencia Social, 15, 15-30.

Cuesta, R. (2014). Genealogía y cambio conceptual. Educación, historia y memoria. Archivos Analíticos de Políticas Educativas 22(23), art 4. doi:10.14507/epaa.v22n23.2014

Cuesta, R. (2015). La venganza de la memoria y las paradojas de la historia. Recuperado de www.lulu.com

Faúndez, X. Cornejo, M. y Brackelaire, J. C. (2013). Transgeneracionalidad del trauma psicosocial: imágenes de la detención de presos políticos de la dictadura militar chilena reconstruidas por los nietos. Psykhe, 22(2), 83-95. doi:10.7764/psykhe.22.2.563

Feld, C. y Garaño, S. (2014). Espacios de memoria; controversias en torno a los usos y las estrategias de representación. Revista del Núcleo de Estudios sobre Memoria, 2, 1-85.

Garcés. M. y Leiva, S. (2005). El golpe en la legua. Los caminos de la historia y la memoria. Santiago: LOM

Garretón, M. A. (2003). Memoria y proyecto país. Revista de Ciencia Política, 23(2), 215-230. doi: $10.4067 / \mathrm{s} 0718-090 \times 2003000200010$

Garretón, M. A. y Garretón, R. (2010). La democracia incompleta en Chile. La realidad de los rankings internacionales. Revista de Ciencia Política, 30(1), 115-148.

Gentile, M. B. (2015). El recuerdo del mal: Historizar la memoria. Revista El Ágora, 15(2), 365374. doi:10.21500/16578031.1619

Giroux, H. (2003). Pedagogía y política de la esperanza. Buenos Aires: Amorroutu.

González, R., Manzi, J. y Noor, M. (2013). Identidad Social y emociones intergrupales: antecedentes de las actitudes de perdón y reparación política en chile. Psyke, 22(2), 129146. doi:10.7764/psykhe.22.2.575

Jaramillo, J. (2009). Tres experiencias emblemáticas de recuperación de pasados violentos en América Latina. Argentina, Guatemala y Colombia. Antropología Social, 11, 29-59.

Jelin, E. (2002). Los trabajos de la memoria. Memorias de la represión. Madrid: Siglo XXI.

Jelin, E. (2003). Los derechos humanos y la memoria de la violencia política y la represión: la construcción de un campo nuevo en las ciencias sociales. Recuperado de http://ides.org.ar/wpcontent/uploads/2012/03/cuaderno2_Jelin.pdf

Jelin, E. (2014). Las múltiples temporalidades del testimonio. El pasado vivido y sus legados presentes. Clepsidra, 1(1), 140-163.

Kosseleck, R. (1994). Futuro pasado para una semántica de los tiempos históricos. Barcelona: Paidós.

Lira, E. (2010). Memoria y convivencia Democrática. Políticas de olvido y memoria. San José: FLACSO.

Lechner, N. (2002). Las sombras del mañana. La dimensión subjetiva de la política. Santiago: LOM. 
Lechner, N. y Güell, P. (2006). La construcción social de las memorias en la transición chilena. En E. Jelin y S. Kaufman (Comps.), Subjetividad y figuras de la memoria. Memorias de la represión (pp. 17-46). Buenos Aires: Siglo XXI.

Lefranc, S (2004). Políticas del perdón. Bogotá: Norma.

Hirsch, M. (2008). The generation of postmemory. Poetics Today, 29(1), 103-128. doi: $10.1215 / 03335372-2007-019$

Hunneus, C. y Ibarra, S. (2013). La memoria del régimen de Pinochet desde la opinión pública. En K. Collins y A. Joignat (Eds.), Las políticas de la memoria en Chile: Desde Pinochet a Bachelet (pp. 227-264). Santiago: Ediciones Universidad Diego Portales.

Hunneus, C. (2014). La democracia semisoberana. Chile después de Pinochet. Santiago: Taurus.

Mate, R. (2006). Medianoche en la historia. Comentarios a las tesis de Walter Benjamin. Sobre el concepto de historia. Madrid: Trotta.

Mate, R (2009). La herencia del olvido. Madrid: Errata Naturae.

Mayol, A. (2014). El derrumbe del modelo. La crisis de la economía del mercado en el Chile contemporáneo. Santiago: LOM

Mélich, J. C. (2004). La lección de Auschwitz. Barcelona: Herder.

Mendoza, C. (2015). Políticas de la memoria y transmisión generacional de pasados recientes. Ciudad de Mexico: Universidad Nacional Autónoma de México.

Montealegre, J. (2013). Memoria Eclipsadas. Santiago: LOM.

Moulián, T. (1998). Chile actual. Anatomía de un mito. Santiago: LOM.

Mudrovic, M. I. (2005). Historia, narración y memoria. Los debates actuales en filosofía de la historia. Madrid: Akal.

Mudrovic, M. I. (2014). Regímenes de historicidad y regímenes historiográficos: del pasado histórico al pasado presente. Historiografía, 5, 11-31.

OPCIÓN-ECEN. (2013). Los ruidos del silencio. Los niños, niñas y adolescentes hablan a cuarenta años del golpe militar en Chile. http://www.opcion.cl/

Osorio, J. (2016). Ciudadanías en movimiento: hacia una agenda de educación ciudadana crítica. Education Global Research, 9, 20-33.

Osorio, J. y Rubio, G (2006). El deseo de la memoria. Escritura e historia. Santiago: Escuela de Humanidades y Política.

Piper, I., Fernández, R. e Iñiguez-Rueda, L. (2013). Psicología social de la memoria. Espacios y políticas del recuerdo. Psyke, 22(2), 19-31. doi: 10.7764/psykhe.22.2.574

Piper, I. (2015). Violencia política. Miedo y amenaza en lugares de memoria. Athenea Digital, $15(4), 155-172$.

PNUD. (2015). Los tiempos de la politización. Recuperado dehttp://desarrollohumano.cl/idh/

Quintar, E. (2015). Memoria e Historia. Desafíos a las prácticas políticas del olvido en América Latina. Agora, 15(2), 375-391. doi: 10.21500/16578031.1620

Rama, A. (2004). La ciudad letrada. Santiago: Tajamar Editores.

Reyes, M. J., Cornejo. M., Cruz, M. A., Carrillo, C. y Caviedes, P. (2014). Dialogía intergeneracional de memorias acerca de la dictadura militar chilena. Universitas Psychologica, 14(1), 255-270. 
Reyes, M. J., Cruz, M. A. y Aguirre, F. J (2016). Los lugares de la memoria. Algunos efectos políticos de la transición del pasado reciente de Chile. Revista Española de Ciencia Política, 4, 93-114. doi: 10.21308/recp.41.04

Richard, N. (2010). Crítica de la memoria. 1990-2010. Santiago: Cuarto Propio.

Ricoeur, P. (2004). La Historia la memoria y el olvido. Buenos Aires: Fondo de Cultura Económica.

Rosanvallon, P. (2007). La contrademocracia. La Política en la era de la desconfianza. Buenos Aires: Manantial.

Rubio, G. (2013). Memoria política y pedagogía. Los caminos hacia la enseñanza del pasado reciente. Santiago: LOM.

Rubio, G. (2014). Memoria histórica, ciudadanía y crisis moral de la esfera pública. Chile a 40 años del golpe militar de 1973. Recuperado de http://revistas.uv.mx/index.php/Clivajes

Rubio, G. (2016). Memoria hegemónica y memoria social. Tensiones y desafíos pedagógicos en torno al pasado reciente. Revista Colombiana de Educación (7),109-135.

Rubio, G. (s/f). Notas para las capacidades de una ciudadanía memorial. Manuscrito de la autora.

Ruiz Torres, P. (2007). Los discursos de la memoria histórica en España. Revista de Historia Contemporánea, 7, 5-30.

Sacavino, S. (2015). Pedagogía de la memoria y educación para el nunca más para la construcción de la democracia, Folios, 41, 69-85. doi: 10.17227/01234870.41folios69.85

Sánchez, M (2009). Cultura histórica. Recuperado de http://www.culturahistorica.es/

Sepúlveda, M., Sepúlveda. A., Piper, I. y Troncoso, L. (2015). Lugares de memoria y agenciamientos generacionales: lugar, espacio y experiencia. Última Década, 42, 93-113. doi: 10.4067/So718-22362015000100005

Stern, E. (2000). De la memoria suelta a la memoria emblemática: Hacia el recordar y el olvidar como proceso histórico. En M. Garcés, M. (Comp.), Memorias para un nuevo siglo. Chile. Miradas a la segunda mitad del siglo XX (p. 11-33). Santiago: Ediciones ECO.

Stern, E. (2013). Memorias en construcción: Los retos del pasado presente en Chile 1989-201 1. Santiago: Museo de la Memoria y los Derechos Humanos.

Timmermann, F. (2015). El gran terror. Miedo, emoción y discurso. Chile, 1973-1980. Santiago: Ediciones Copygraph.

Tocornal, X. (2010). Chile, la memoria dividida. Santiago: Fundación Heinrich Boll.

Veles, G. y Herrera, M. C. (2014). Formación política en el tiempo presente. Ecologías violentas y pedagogía de la memoria. Nómadas, 41, 149-165.

Wilde, A. (2013). Un tiempo de memoria. Los derechos humanos en la larga transición chilena. En K. Collins y A. Joignant (Eds.), Las políticas de la memoria en Chile: Desde Pinochet a Bachelet (pp. 55-84). Santiago: Ediciones Universidad Diego Portales.

Zaliasnick, Y. (2016). Memoria Inquieta. Santiago: Fondo de Cultura Económica.

\section{Breve CV de los autores}

\section{Graciela Alejandra Rubio}

Profesora de estado en Historia y Geografia. Magister en Historia y Doctora en Educacion. Academica del Instituto de Historia y Ciencias Sociales Universidad de 
Valparaíso. Docente de pre y postgrado. Ha desarrollado estudios sobre la memoria historica presente en la discusion publica, los informes de verdad y discusiones sobre la pedagogia de la memoria. Actualmente realiza un estudio sobre las narrativas del curriculum escolar y en jovenes de liceos publicos de Sanatiago y Valparaíso. ORCID ID: 0000-0002-4849-835X. Email: gracia.aleja@gmail.com

\section{Jorge Osorio}

Licenciado en Historia. Diplomado de Postgraduación del International Institute of Social Studies (ISS) de La Haya (Holanda) en Desarrollo y Derechos Humanos. Docente del Departamento de Psicología Educacional de la Escuela de Psicología de la Universidad de Valparaíso y de la Maestría de Educación en Derechos Humanos del Centro de Cooperación para la Educación de Adultos en América Latina y El Caribe, Michoacán, México. ORCID ID: O000-0001-9787-5599. Email: josorio.humanidades@gmail.com 